\title{
Expert System for Diagnosing Damage Genset Petbow on PT.Salim Ivomas Pratama Tbk Method Using Certainty Factor (CF)
}

\author{
Herman Yoga ${ }^{1}$, R.Mahdalena Simanjorang ${ }^{2}$ \\ ${ }^{1.2}$ Informatics Engineering Study Program, STMIK Pelita Nusantara, Jl. Iskandar Muda No. 1 Medan, \\ North Sumatra, Indonesia 20154
}

Email: hermandyoga10@gmail.com

\begin{abstract}
This study aims to design an expert system applications that are made to provide solutions to users in order to Overcome the cause of damage to the generator set. The mechanism of this program works with the Certainty Factor method, while the method used in this research is to collect information about the generator damage from experts systematically compiled into a database on a computer where the database will Determine the solution of the facts. facts on the generator sets entered into this program. The test results of this program will provide a solution to the user quickly intervening after the user Provides information to the program about the state of the generator that is interrupted or damaged.
\end{abstract}

Keywords: Petbow GeneratorDamage, CertaintyFactor, Expert System.

\section{Introduction}

Genset become a tool for generating electrical power backup when an interruption or outage of PLN. Genset is now widely used for the needs of the greater power resources. Industrial companies, non-industrial companies and households in need of generators so that all activities can be run well not disrupted due to interference or power outages included in PT. Salim Ivomas Primary.

PT. Salim Ivomas Pratama Tbk, sometimes resulting disruption reliability decreases and if not addressed can affect the system or even damage to the generator. In anticipation of this event is to know about the symptoms of damage to the generator and any problems to be quickly followed up in the repair of damage to the generator. Because the damage to the generator is generally less well diagnosed with, if not in check and control with every hour of his routine. It is very important for the operator's role in the room is always standby generator set and control the conditions of the generator, in case of a sign which is not normal in the generator as the engine sound harsh, high vibration or choked it should immediately repair the generator as soon as possible.

To make it easier to diagnose damage to the generator, it takes an expert system-based application program. According to Wikipedia is the Expert System is a computer program that contains the knowledge of an expert that can be used in consultation. In order to facilitate later penelitiansistem expert in diagnosing damage to the generator by entering some data like the signs of symptoms of damage to the generator by collecting data by conducting research to an expert in damage to the generator. To assist the passage of an expert system application, the researchers also used the method of Certainty Factor. Certainty Factor Method according to David Mc Allister is a method of proving whether or not the fact it would have been definitely shaped metrics that are typically used in an expert system.

\section{Theory}

\subsection{Expert system}

Expert System is an artificial intelligence program that combines the knowledge base to base inference system to mimic an expert. The expert system is a system that tried to adopt human knowledge into a computer so that the computer can resolve the issue as was done by experts. It is expected that with this expert system, users can solve specific problems, without the help of experts in the field. (Zulfian Azmi, ST, and Verdi Yasin M. Kom, Kom., M. Kom. 2019: 11).

\subsection{Certainty Factor Method}

According to David McAllister (2019: 91) The definition of Certainty Factor (Certainty Factor) is a method to prove whether a fact that certainly would not have been shaped or metric that is usually used in an expert system. Theories of Certainty Factor (CF) proposed by Shortliffe and Buchanan in 1975 to accommodate 
the uncertainty of thought (inexact reasoning) an expert. Certainty Factor introduced the concept of belief and disbelief are then formulated in the formulation of the basic formula. There are two ways in mendaptkan level of confidence $(\mathrm{CF})$ from a rule, namely:

a) Method 'Net Belief' proposed by EHShortliffe and BG BuchananCF (Rule) $=$ MB (H, E) .MD (H, E)

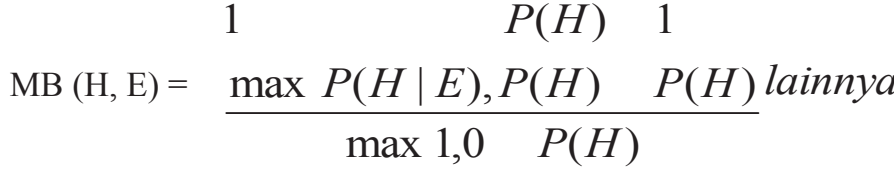

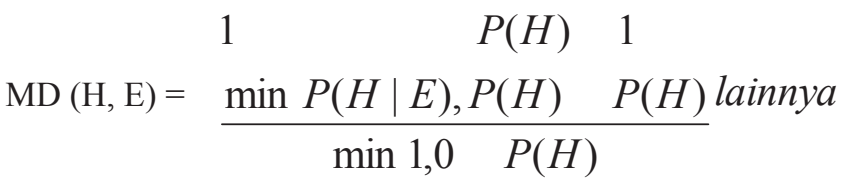

Information:

$\mathrm{CF} \quad$ : Certainty Factor (certainty factor)

$\mathrm{MB}(\mathrm{H}, \mathrm{E}) \quad$ : Measure of Belief (measure of confidence) against the hypothesis $\mathrm{H}$, if given evidence $\mathrm{E}$ (between 0 and 1 )

$\mathrm{MD}(\mathrm{H}, \mathrm{E}) \quad$ : Measure of Belief (a measure of distrust) towards evidence-H, if given evidence $\mathrm{E}$ (between 0 and 1)

$\mathrm{P}(\mathrm{H}) \quad$ : Probability (probability of truth hipotesisH)

$\mathrm{P}(\mathrm{H} \mid \mathrm{E}) \quad$ : BawahH probability of correctly due to the fact $\mathrm{E}$.

\section{Research methods}

The method used in this study are:

a) Analyze Problems, Analysis of the problem that is studying the problems that will be discussed in the study by obtaining data that will be used. In this npenelitian posed problem is the length of a process results in diagnosing damage to the generator, so should we need a system to speed up the handling in diagnosing damage to the generator.

b) Formulating the Problem, At this stage of formulation of the problem to be made is to create a system to make it easier to diagnose damage to the generator. The expert system is a system used in this study.

c) Data Collection, Data Collection in research iiadalah in collecting data Study Library, Interview (Interview) and observation (Observation).

d) Data Analysis, From the data analysis can be summed up some of the criteria that will be used in the system, namely: the symptoms that occur early in damage to the generator. It aims to do the grouping to the data that will allow the research to subsequent analyzes.

e) Algorithm Implementation of Certainty Factor For Diagnosing Damage to the generator, the application of the algorithm with Certainty Factor method to diagnose damage to the generator, so that will find results from damage to the generator.

f) System Design, In this study, there are several steps in designing a system include: shape / appearance of design is made in accordance with kebutuhantempat research.

g) Testing, testing was conducted to determine the errors that may occur in the coding process and to ensure that input is bounded deliver results in accordance with the needs.

\section{Results and Discussion}

Methods that researchers use in the writing of this expert system is the certainty factor method, there are some steps or stages of data sebagaiberikut method:

Damage Batteries Weak or Damaged

$$
\begin{aligned}
& G 1 \text { AND G2 } \\
& =0.3+0.2 *(1-0.3)=0.44 \\
& G 1 \text { AND G2 AND G5 } \\
& =0.44+0.1 *(1-0.44)=0,496 \\
& G 1 \mathrm{G} 2 \text { AND AND AND G5 G6 } \\
& =0,496+0.1 *(1-0.496)=0.5464 \\
& G 1 \mathrm{G} 5 \mathrm{G} 2 \text { AND AND AND AND G6 G9 } \\
& =0.5464+0 *(1-0.5464)=0.5464
\end{aligned}
$$


Damage solenoid Damaged

G1 AND G2

$=0+0 *(1-0)=0$

G1 AND G2 AND G5

$=0+0 *(1-0)=0$

G1 G2 AND AND AND G5 G6

$=0+0.1 *(1-0)=0.1$

G1 G5 G2 AND AND AND AND G6 G9

$=0.1+0.1 *(1-0.1)=0.19$

Damage Voltage Voltage Not Quit or Not suitable

G1 AND G2

$=0+0 *(1-0)=0$

G1 AND G2 AND G5

$=0+0 *(1-0)=0$

G1 G2 AND AND AND G5 G6

$=0+0 *(1-0)=0$

G1 G5 G2 AND AND AND AND G6 G9

$=0+0 *(1-0)=0$

keruskan disturbance Burning

G1 AND G2

$=0+0 *(1-0)=0$

G1 AND G2 AND G5

$=0+0 *(1-0)=0$

G1 G2 AND AND AND G5 G6

$=0+0 *(1-0)=0$

G1 G5 G2 AND AND AND AND G6 G9

$=0+0 *(1-0)=0$

Damage Faulty control relay

G1 AND G2

$=0+0 *(1-0)=0$

G1 AND G2 AND G5

$=0+0 *(1-0)=0$

G1 G2 AND AND AND G5 G6

$=0+0 *(1-0)=0$

G1 G5 G2 AND AND AND AND G6 G9

$=0+0 *(1-0)=0$

$\mathrm{CF}$ greatest value

Max (CF H01, H02 CF, CF H03, H04 CF, CF H05 = $(0.5464,0.19,0,0,0)$

$\mathrm{CF} \mathrm{H01}=0.5464$

So based on the identification has been done it can be concluded that the generator engine damage Weak or Damaged Batrai with certainty the level of 0.5464 or with the percentage of $54.64 \%$.

\section{Conclusion}

Based on the discussion regarding Diagnosing malaria with Bayes method it can be concluded:

a) Build an expert system application using CertaintyFactor method for diagnosing damage to the generator requires some supporting facilities required by both the system hardware and software.

b) Application of Certainty Factor method to diagnose the damage of generators in PT Salim Ivomas Pratama Tbk required data will be inputted into the system, processed and display generator damage diagnosis and repair solutions.

\section{Reference}

[1] Bhaskara Adhi Pradhana, 2013. Design Expert System For Laptop Hardware Damage Diagnosis Method Using Certainty Factor.

[2] Budi Saputro, 2017. Analysis of Reliability Generator Set As Power Supply Emergency Power Supply From PLN If suddenly Padam in Morodadi Poultry Shop Blitar, Teknika Qua Journal, Vol. 7 No. 2.

[3] Echoes Dirgantara Putra Rimba, Suprapto, Bayu Rahayudi, 2018. Implementation of Certainty Factor Method In Damage Identification of Two-Wheeled Vehicle. Development Journal of Information Technology and Computer Science Vol. 2 No. 6. 